I N S T I T U T O

DE

M E D I C I N A

T R O P I C A L

DE

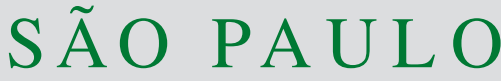

JOURNAL OF THE SÃO PAULO INSTITUTE OF TROPICAL MEDICINE

(1) Universidade Federal do Rio de Janeiro, Hospital Universitário Clementino Fraga Filho, Serviço de Dermatologia, Rio de Janeiro, Rio de Janeiro, Brazil

(2) Universidade Federal do Rio de Janeiro, Hospital Universitário Clementino Fraga Filho, Curso de Especialização em Dermatologia, Rio de Janeiro, Rio de Janeiro, Brazil

(3) Universidade Federal do Rio de Janeiro, Hospital Universitário Clementino Fraga Filho, Laboratório de Micologia, Rio de Janeiro, Rio de Janeiro, Brazil

(4) Universidade Federal do Rio de Janeiro, Hospital Universitário Clementino Fraga Filho, Departamento de Patologia, Rio de Janeiro, Rio de Janeiro, Brazil

(5) Instituto de Pesquisa Clínica Evandro Chagas, FIOCRUZ, Rio de Janeiro, Rio de Janeiro, Brazil

Correspondence to: Nurimar C. Fernandes Universidade Federal do Rio de Janeiro, Hospital Universitário Clementino Fraga Filho, Serviço de Dermatologia, 5ํandar, CEP 21941-913, Rio de Janeiro, RJ, Brazil Tel: $+55213938-2580$

E-mail: nurimarfernandes@terra.com.br

Received: 23 September 2016

Accepted: 22 February 2017
http://dx.doi.org/10.1590/S1678-9946201759036

\section{Sarcoid-like cutaneous lesions in chronic adult paracoccidioidomycosis: report of two cases}

\author{
Nurimar C. Fernandes ${ }^{1}$, Júlia Gomes Côrtes ${ }^{2}$, Tiyomi Akitti ${ }^{3}$, Danielle \\ Carvalho Quintella ${ }^{4}$, Tulia Cuzzi ${ }^{1,5}$
}

\section{ABSTRACT}

This study reports two cases of chronic paracoccidioidomycosis with sarcoid-like cutaneous lesions. The patients began the treatment in 2013 at Hospital Universitário Clementino Fraga Filho (HUCFF) of the Universidade Federal do Rio de Janeiro (UFRJ). The first case (mild form) was treated with trimethoprim-sulfamethoxazole ( $8 \mathrm{mg} / \mathrm{kg}$ per day, orally) for three months and, then, with half the dose for nine months; the second (moderate form), with itraconazole (200 mg per day, orally) for 12 months. We point out the rareness of the sarcoid-like cutaneous lesions and the differential diagnoses for other granulomatous diseases.

KEYWORDS: Paracoccidioidomycosis. Sarcoidosis. Epidemiology. Diagnosis. Classification.

\section{INTRODUCTION}

Paracoccidiodomycosis is a systemic mycosis with acute and chronic progression, caused by Paracoccidioides species. Studies reveal that the male/female rate is $6: 1$; there is a prevalence of the chronic clinical form in adults (74.6\%); the absolute majority of patients have a rural life history (93.5\%), with high rates of smoking $(64.7 \%)$ and alcohol abuse $(37.2 \%)^{1,2}$.

Sarcoidosis is a systemic disease of unknown cause, characterized by the formation of epithelioid cell granulomas in the affected organs. It affects men and women of all races and ages, usually between 20 and 40 years old, with a slight predominance in women.

The morphological variety of the sarcoidosis lesions leads to the following differential diagnoses: secondary/tertiary syphilis, granuloma annulare, tuberculoid leprosy, lupus vulgaris and lupus erythematosus ${ }^{3}$.

Paracoccidiodomycosis can manifest itself through sarcoid-like cutaneous lesions ${ }^{4-6}$, i.e., well-defined and infiltrative lesions, generally in the cephalic pole. According to the description of Brazilian adults ${ }^{4}$, histology in these cases shows a tuberculoid, granulomatous, inflammatory pattern with a paucity of fungi. Patients are young and may have cervical lymph nodes, but the overall condition is good. Skin lesions in paracoccidioidomycosis occur in $30-54 \%$ of patients ${ }^{4}$. They are most commonly located on the face with an ulcerative-vegetative pattern, usually followed by infiltration ${ }^{4,7}$.

\section{FIRST CASE REPORT}

A 49 years old, male, metallurgical employee born and raised in Nova Iguaçu 
(urban area), Rio de Janeiro State. This case evolved for four months with injuries on the face, scalp, and right preauricular region. He showed no lesions in the oral mucosa. The patient was examined by a private physician who, due to a positive ANA test (1/160) and cutaneous involvement, began treatment for systemic lupus erythematosus (SLE) with oral hydroxychloroquine $400 \mathrm{mg}$ each day and prednisone $40 \mathrm{mg}$ per day.

In May 2013, the patient was referred to Hospital Universitário Clementino Fraga Filho (HUCFF) of the Universidade Federal do Rio de Janeiro (UFRJ), more precisely to the Dermatology Service; he had been sick since December, 2012.

He denied drinking alcohol and smoking. Dermatological examination indicated erythematous infiltrated, ulcerated, and crusted lesion in left malar region, and ulcerousvegetating lesion on the right preauricular region (Figure 1A). Complete blood count, liver and renal functions, erythrocyte sedimentation rate (ESR), anti-HIV serology, anti-Sm, antiDNA, and chest X-ray (PA and lateral) were requested. The results showed: normal values for blood count, liver and renal functions, and erythrocyte sedimentation rate; negative anti-HIV serology; negative anti-Sm; negative anti-DNA; and normal chest X-ray. Weaning from prednisone was started and hydroxychloroquine was suspended.
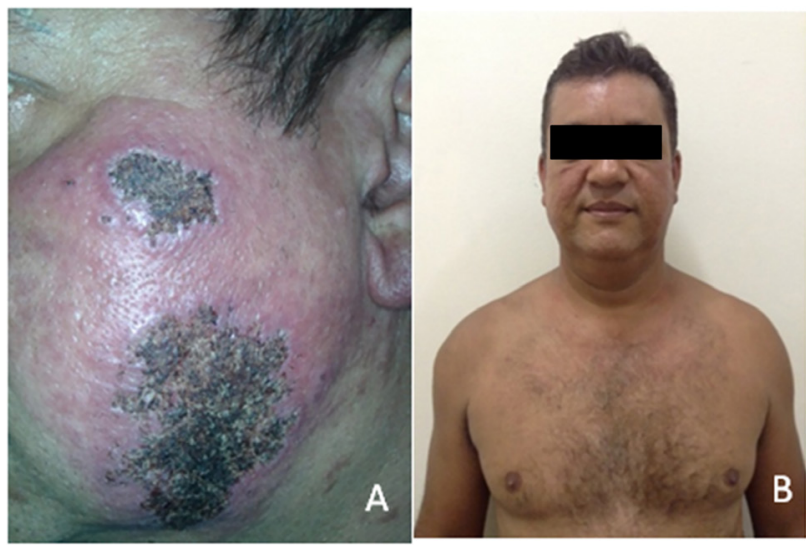

Figure 1 - (A) Erythematous infiltrated plaque, crusted and ulcerated on the left malar area; (B) Complete involution of the lesions after six months' treatment (Case 1)

The histopathological examination of skin fragment obtained by biopsy revealed fungal elements (Figure 2).

The biopsy material was placed on a slide with a drop of black ink Parker $+20 \%$ potassium hydroxide $(\mathrm{KOH})$ solution, examined under the microscope, and revealed the yeast cells: multiple buds attached to the mother cell (resembling a pilot's wheel) by very narrow necks, characteristic of Paracoccidioides spp. (Figure 3).

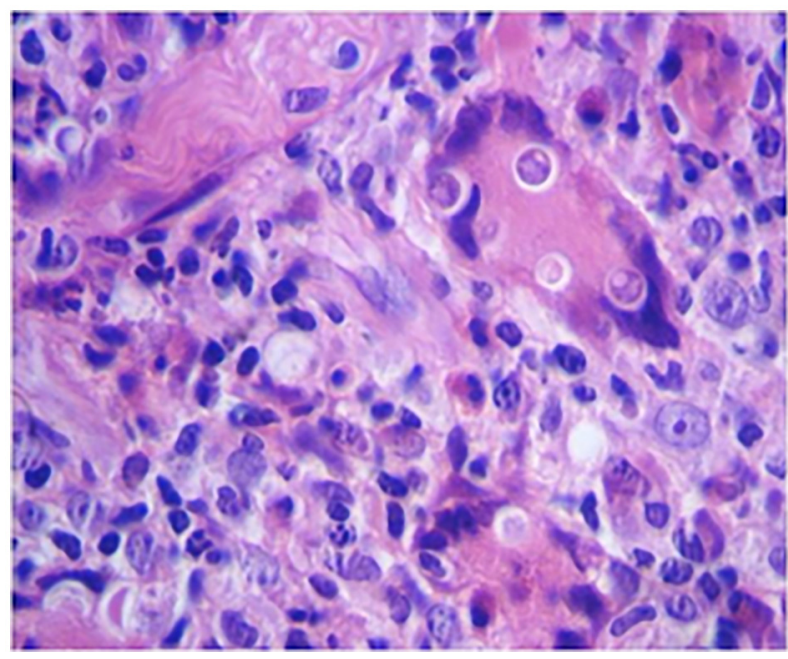

Figure 2 - Chronic granulomatous inflammation with yeast cells inside multinucleated giant cells. H\&E (x40) (Case 1)

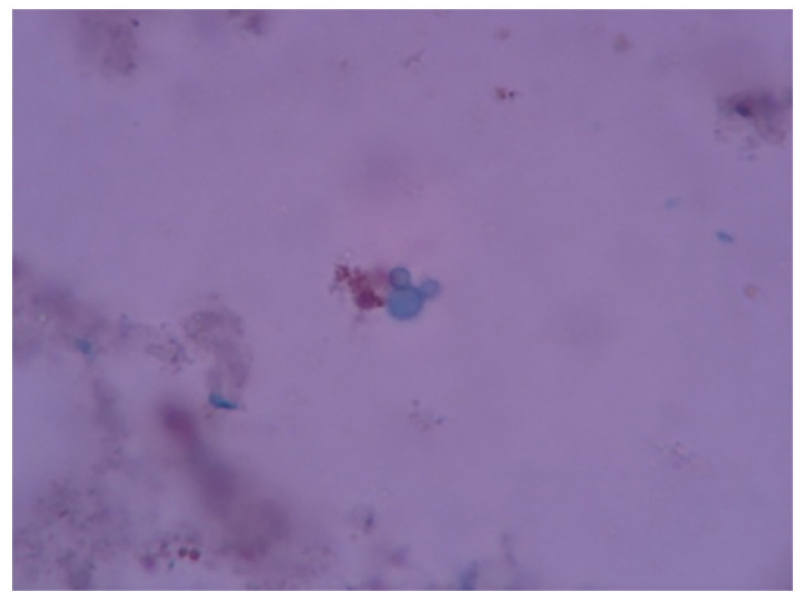

Figure 3 - Direct examination: -globular cells with thick walls and multiple budding. Black ink Parker with $20 \% \mathrm{KOH}-(40 \mathrm{x})$ (Case 1)

The clinical presentation of the disease was evaluated as mild by the following parameters: absence of fever, loss of weight, palpable lymph nodes, and pulmonary involvement, no impairment of general condition. Trimethoprim sulfamethoxazole was initiated at an oral dose of $8 \mathrm{mg} / \mathrm{kg} / \mathrm{day}$ (trimethoprim) for three months and, then, half of the dose for nine months ${ }^{2}$. There was complete regression of the lesions before six months (Figure 1B).

\section{SECOND CASE REPORT}

A 56 years old, male, machine operator, born and raised in Itatiaia (urban area), Rio de Janeiro State. The disease started in November 2012 with bilateral cervical lymphadenopathy, associated with node suppuration and fever. After six months, the patient was referred to Hospital Universitário Clementino Fraga Filho (HUCFF) of the Universidade Federal do Rio de Janeiro (UFRJ), more 
precisely to the Dermatology Service, due to erythematousviolaceous infiltrated plaques, some scaly on the face, trunk and limbs (Figure 4A). Complete blood count, erythrocyte sedimentation rate, liver and renal functions, anti-HIV serology, and chest X-ray (PA and lateral) were requested. The results showed: normal values for blood count, erythrocyte sedimentation rate, liver and renal functions; negative anti-HIV serology; normal chest X-ray.

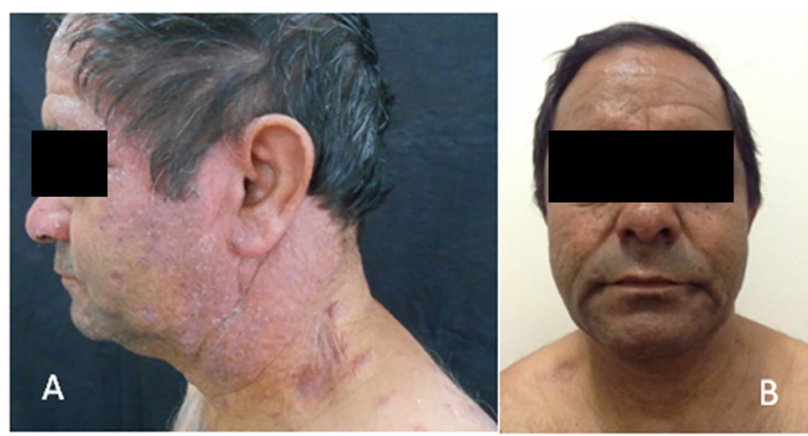

Figure 4 - (A) Erythematous violaceous and infiltrated plaques of face, trunk and limbs; (B) Regression of the lesions after six months' treatment (Case 2)

The histopathological examination of skin fragment obtained by biopsy revealed scarce, round and smooth, fungal elements (Figure 5).

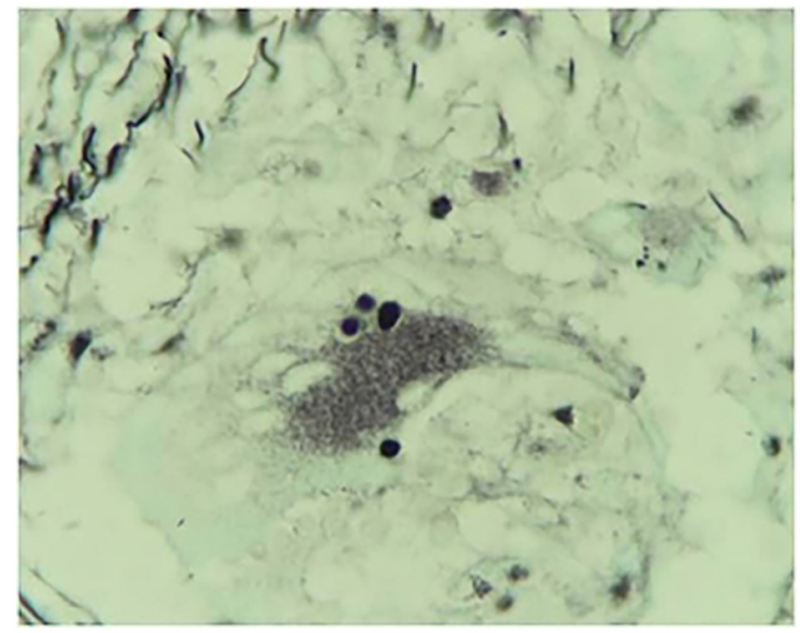

Figure 5 - Rare globular, regular, fungal cells. Silver (x40) (Case 2)

In order to isolate the fungus, the material from skin biopsy was plated on Sabouraud's agar and incubated at $25-30^{\circ} \mathrm{C}$

Conversion of the mycelial culture to the yeast form in vitro was achieved by transferring into brain-heart infusion and incubating at $37{ }^{\circ} \mathrm{C}$ for 20 days with profuse yeast cells bud production, characteristic of Paracoccidioides spp. (Figure 6).

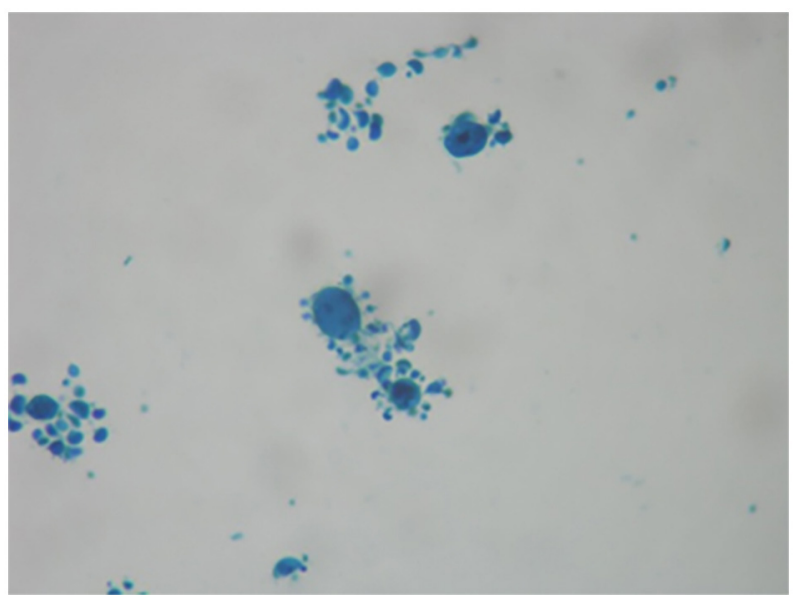

Figure 6 - Isolation of the fungus in the yeast form: yeast cells with multiple buds. Lactophenol cotton blue (40x) (Case 2)

The clinical presentation of the disease was evaluated as moderate by the parameters fever and suppurative lymphadenopathy. Thus, itraconazole was initiated at an oral dose of $200 \mathrm{mg}$ after lunch, in a single administration per day for 12 months. There was complete regression of the disease ${ }^{2}$ (Figure 4B).

\section{DISCUSSION}

One of the described patients was referred to HUCFF with a diagnosis of cutaneous lupus erythematosus, in use of oral corticosteroids and hydroxychloroquine. In the tumid variety, the lesions are edematous and infiltrated with erythematous surface of varying sizes. It is the clinical form, which includes sarcoidosis as a differential diagnosis.

In chronic lupus erythematosus, the main age distribution is adults aged 20-40 and above 70. It is more common in Caucasian women in the proportion of 3.4:1.0.

Despite the rareness of ulcerative lesions in sarcoidosis, they may occur (first case), as already reported in the literature ${ }^{8,9}$

Some authors ${ }^{4,5,6}$ believe that the sarcoid form is determined by good specific immunity against Paracoccidiodes spp. The biggest challenge in infectious granulomatous diseases without obvious etiology is endurance and persistence in research until the agent is found ${ }^{4}$, besides the inherent difficulties in the diagnosis of cutaneous sarcoidosis itself.

\section{REFERENCES}

1. Bellisimo-Rodrigues F, Machado AA, Martinez R. Paracoccidioidomycosis epidemiological features of a 1,000case series from a hyperendemic area on the southeast of Brazil. Am J Trop Med Hyg. 2011;85(3):546-50. 
2. Shikanai-Yasuda MA, Telles Filho FQ, Mendes RP, Colombo AL Moretti ML. Consenso em paracoccidioidomicose. Rev Soc Bras Med Trop. 2006;39(3):297-310.

3. Freitas TH, Ribeiro AE. Lúpus eritematoso. In: Ramos-e-Silva M, Castro MC, editores. Fundamentos de dermatologia. Rio de Janeiro: Atheneu; 2009. p.1225-53.

4. Marques SA, Lastória JC, Putinatti MS, Camargo RM, Marques ME. Paracoccidiodomycosis: infiltrated, sarcoid-like cutaneous lesions misinterpreted as tuberculoid leprosy. Rev Inst Med Trop São Paulo. 2008;50(1):47-50.

5. Nascimento CR, Delanina WF, Soares CT. Paracoccidioidomycosis: sarcoid-like form in childhood. An Bras Dermatol. 2012;87(3):486-7.
6. Müller SF, Miranda MF. Sarcoid-like paracoccidioidomycosis presenting with perineural granuloma. An Bras Dermatol. 2013;88(6):994-5.

7. Proença NG, Pedrozo BR, Muler H, Kliemann TA. Dificuldades para diagnóstico de sarcoidose exclusivamente cutânea. AMB Rev Assoc Med Bras. 1984;30(5-6):101-4.

8. Dinato SL, Lavedonio SE, Santos NR. Lesões cutâneo-ulcerosas na sarcoidose. An Bras Dermatol. 1996;71(6):491-4.

9. Brenner FM, Badziak D, Rosas FM, Fillus Neto J, Moritz S. Alopécia: manifestação cutânea rara de sarcoidose. An Bras Dermatol. 2008;83(5):437-40. 